УДК 376:3:373.2:15154.6

DOI $10.21661 / \mathrm{r}-118699$

Г.Ж. Шамканова

ПЕДАГОГИЧЕСКОЕ ОБОСНОВАНИЕ МЕТОДИКИ ПРИМЕНЕНИЯ НАПРАВЛЕННЫХ ФИЗИЧЕСКИХ УПРАЖНЕНИЙ НА РАЗВИТИЕ МЕТОДИКИ РУК ДЛЯ ПОВЫШЕНИЯ РЕЧЕВОЙ КУЛЬТУРЫ ДОШКОЛЬНИКА

Аннотация: в данной статье рассматривается вопросы о комплексной программе сенсорномоторного развития, направленной на развитие ритма и моторики рук средствами физического воспитания и создающей зону развития всех сторон психики, моторики и речи ребенка.

Ключевые слова: дети, дошкольники, культура речи, психика, ритмика, метод, эксперимент, интеллектуальность, физические упражнения, двигательные деятельности.

\title{
G.Zh. Shamkanova
}

\section{DISCUSSION OF IMPLEMENTATION OF PHYSICAL EXERCISES FROM PEDAGOGICAL POINT OF VIEW TO DEVELOP THE METHODS OF HAND TO IMPROVE PRESCHOOLER'S SPEECH CULTURE}

Abstract: this article discusses the issues of a comprehensive program of sensory-motor development aimed at the development of rhythm and hand movements by means of physical education and by creating a zone for the development of all aspects of the mind, speech and motor skills of the child.

Keywords: children, preschoolers, speech culture, state of mind, rhythmic, technique, exeperiment, intelligence, physical activity, motor activity.

Педагогическая наука считает формирование речевой культуры дошкольников средствами физической культуры одной из существенных сторон подготовки детей. При этом обращает особое внимание, что данный педагогический процесс должен строиться с учетом будущей деятельности (учебной), возраста, 
состояния здоровья, уровня умственного, психического, физического развития и некоторых других факторов. Однако обоснование влияния методики развития ритма, моторики рук посредством физических упражнений на развитие речи детей 3-5 лет в дошкольных образовательных учреждениях в обсуждаемом плане должного обоснования еще не получила. Этот факт упоминается главным образом в постановочном плане, указывается среди особых требований к уровню физического и психического развития детей.

При обсуждении вопросов конкретной методики проведения методики развития координационных способностей пальцев рук, культуры речи, посредством физических упражнений, специалисты акцентирует внимание на необходимости особого подхода к определению средств и методов формирования детей с учетом будущей учебной деятельности. Вместе с тем результаты опроса респондентов и педагогических наблюдений за занятиями детей свидетельствует в том. что данное положение не получает должной реализации в практике работы с детьми в ДОУ. Более того, предлагаемые детям средства и методы формирования моторики рук и посредством физических упражнений на развитие речи детей даются без основательного учета особенностей, свойственных их предстоящей учебной деятельности.

Указанное обстоятельство поставило нас перед задачей «экспериментальное обоснование методику применения направленных ритмических физических упражнений на развитие моторики рук для повышения речевой культуры дошкольника. Как нам представляется, на этой основе можно и нужно осуществлять взвешенный профессионально обоснованный подбор разнообразных педагогических воздействий на детей, обеспечивающих эффективное влияние на умственных, психофизических качеств и свойств и в конечном счете на ведущие показатели; состояние с физического развития, психических свойств и т. П. [3].

Отсюда и вытекает общая направленность, сбора, анализа и обобщение собственного научного материала по избранной теме исследования. В этих целях изучено методологические и методические предпосылки изыскательской 
работы среди детей дошкольного возраста, выявлена общая нагрузка на детей, определена готовность (возможность) организма к нагрузкам обоснованы педагогические условия, средства и методы повышения эффективности методики применения направленных ритмических физических упражнений на развитие моторики рук для повышения речевой культуры детей.

Результаты изучения литературы показывают, что в настоящее время, данные направления в повышении формирования культуры речи посредством физических упражнений разработаны недостаточно.

Литературные источники [4; 6], указывают на важное значение развития культуры речи детей. Данное положение чрезвычайно актуально, так как дети дошкольного возраста имеют повышенную умственную, психологическую и эмоциональную нагрузку, которая при не правильной дозировке может привести к различным патологическим изменениям и нарушениям. В методике проведения занятий физическими упражнениями детей, недостаточно выделены критерии здоровья детей. Литература не позволяет воспитателям, методистам, врачам, и иным лицам дифференцировать здоровья детей на группы, чтобы рационально формировать культуры речи детей посредством физических упражнений.

В развитии моторики рук дети 3-х летнего возраста характеризуются слабой способностью к мануальной координации. Период высокой чувствительного развития мануальной координированности приходится на возраст 4 года $[1 ; 2 ; 5]$.

Дети в 3-х летнем возрасте проявляют слабую способность к систематизации в мышлении. Результаты, полученные в тестах с оперированием с предметами, чем в тестах наглядно- образного мышления. Корреляционный анализ подтверждает, что в этом возрасте влияние на развитие интеллекта оказывает моделирование.

В 4-х летнем возрасте, на развитие интеллекта оказывают влияние степень сформированности наглядно-действенного $(0,71)$ и наглядно-образного $(0,69)$ мышления. 
Дети 5-ти летнего возраста отличаются от детей 4-х лет по показателям выполнения тестов, определяющим уровень наглядно- действенного и наглядно - образного мышления. Обнаруживается связь интеллектуального развития с сознательностью действия $(0,71)$ и наглядно-образным мышлением $(0,62)$. Период высокой чувствительности и развитии наглядно-действенного мышления падает на 3-4 лет, а наглядно-образного от 4-х лет.

В звуковой культуре речи выявлено, что период 3-5 лет характеризуется слабым артикуляционными способностями.

В состав средств физического воспитания детей целесообразно включить ритмическая и пальчиковая гимнастика, игрушки и игры для комплексного формирования навыков и умений, представленных в программе сенсорномоторного развития и формирования звуковой культуры речи.

Эффективность организации комплексного физического воспитания, подтверждается следующими данными: достоверность различая в координационных способностях моторики рук между контрольной и экспериментальной группами выявлена во всех исследуемых возрастных группах; выявлена различия контрольной к экспериментальной групп в произношении сложных в артикуляционном плане звуков. В группе свистящих достоверность различий в 3-летнем возрасте достоверность составила $\mathrm{P}<0,05$, а 4-летнем $\mathrm{P}<00,1$. В группе шипящих - в 4-летнем возрасте различия достоверны - $\mathrm{P}<0,01$, а в группе 5-летних детей - $\mathrm{P}<0,05$. В группе сонорных результативность воздействия эффективна в этот период всех возрастных группах.

В тесте выкладывания разноцветных палочек рядов у детей 3-летнего возраста ЭГ получены достоверно высокие показатели, чем в контрольной (P <0,01). В тесте, определяющем степень сформированности логического мышления при выкладывании фигур по размеру, достоверность различии между группами составила в 3- и 4-летнем возрастах $(\mathrm{P}<0,01)$, у детей 5-летнего возраста (Р < 0,05). Сенсорные эталоны приобретают значимость в моделировании, где у детей 3- и 4-летнего возраста получены достоверные степени различия, ( $\mathrm{P}<0,05$ и $\mathrm{P}<0,01)$ соответственно. Дети 4- и 5-летнего возраста ЭГ де- 
монстрируют более высокие показатели чем в КГ в тестах определяющих наглядно-образное мышление $(\mathrm{P}<0,01)$.

Упражнения для формирования моторики рук, подкрепленные словесной и игровой формулировками, позволяют на высокоэмоциональном, осознанном уровне достичь улучшения звукопроизношения. Становлению звуковой культуры речи в детском возрасте способствует развитие речи и мануальной координации [4].

Результаты исследования убеждают в необходимости дальнейшего совершенствования занятий по формированию культуры речи в занятиях физической культурой детей 3-5 лет. Вместе с тем, они же говорят в том, что общепринятая методика работы с ними не заслуживает должной положительной оценки. Более того, в своих принципиальных чертах она должна рассматриваться как вы верный базовой вариант. Об этом свидетельствуют существенные изменения в уровне подготовленности детей КГ (Р < 0,05). Тем не менее на этом фоне ЭГ добиваются заметно более высоких показателей $(\mathrm{P}<0,05)$.

Таким образом, исследование формирования культуры речи посредством физических упражнений с детьми показало, что уровень умственной, психофизической подготовленности детей зависит как от общих, так и специальных педагогических факторов, которые выступают в постоянной динамической связи. Такая связь является закономерной и должна предопределять суть подхода к разработке средств и методов формирования культуры речи и методики проведения занятий с детьми.

И все это свидетельствует о весомом значении повышения занятий с эффективностью, необходимой для полноценной их познавательной, игровой и иной деятельности детей.

Результаты экспериментальной работы подтверждают предположение о взаимосвязи координационных способностей пальцев рук и развития речи, а также влияния специальных физических упражнений на все стороны развития ребенка. 
Предложенные физические упражнения и игры влияют на психические процессы, развития ребенка и приспосабливая к внешним раздражителям.

Координационные способности и развитие моторики рук, подкрепленные игровой деятельностью и развитием ритма, положительно влияют на психические процессы ребенка и их эмоциональный настрой.

\section{Список литературы}

1. Анаркулов Х.Ф. Кыргызские народные подвижные игры и физические упражнения: Учебное пособие. - Бишкек: КГИФК, 2003. - 167 с.

2. Андриянова Е.Ю. Коррекция физического состояния детей дошкольного возраста средствами физической культуры: Автореф. дис. ... канд. пед. наук: 13.00.04 / Е.Ю. Андриянова. - М., 2001. - 21 с.

3. Буцинская П.П. Общеразвивающие упражнения в детском саду / П.П. Буцинская. - М.: Просвещение, 1990. - 175 с.

4. Глазырина Л.Д. Научно-методические основы реализации оздоровительного, воспитательного и образовательного направлений программы физического воспитания дошкольников: Автореф. дис. ... д-ра пед. наук: 13.00.04 / Л.Д. Глазырина. - Минск, 1992. - 41 с.

5. Умурбекова Т.А. Кыргызской народный фольклор о физическом воспитаний дошкольников: Дис. ... канд. пед. наук: 13.00.01 / Т.А. Умурбекова. Бишкек, 2013. - 146 c.

Шамканова Гульмира Жылкычиевна - старший преподаватель Кыргызского государственного университета им. И. Арабаева, Бишкек, Кыргызстан.

Shamkanova Gulmira Zhylkychievna - senior lecturer of I. Abaev Kyrgyz State University, Bishkek, Kyrgyzstan. 